\title{
Production of Red Wine Polyphenols as Ingredient for the Food and Pharmaceutical Industry
}

\author{
Gabriele Di Giacomo*, Luca Taglieri \\ Department of Chemistry, Chemical Engineering and Materials, University of L'Aquila, L'Aquila, I-67100, Italy
}

\begin{abstract}
A selected reverse osmosis based industrial process was developed and validated at pilot plant scale for producing red wine polyphenols dealcoholized and/or concentrated solutions and pastes, starting from red wine as raw material. These ingredients can be used for making new functional products for the food and beverages industry. Comparison with competitive technologies is made, accounting for energy consumption and process operating parameters to avoid damage to the RWP antioxidant functionality. In addition criteria for selecting between different available raw materials and different possible products are discussed with reference to up-stream and down-stream operations, dietary reference intake (DRI) and shelf-life of each ingredients.
\end{abstract}

Keywords Antioxidants, Red Wine, Polyphenols, Reverse Osmosis, Dietary Supplements

\section{Introduction}

A recent studies[1] scientifically supported the "French paradox" that the incidence of coronary heart disease is relatively low in southern France despite high dietary intake of saturated fats[2]. In particular, it has been proved the influence of the red wine polyphenols (RWP) on levels of malondialdehyde (MDA), a by-product of fat metabolism known to increase the risk of heart disease. By using, for the first time, 10 healthy volunteers it was demonstrated that plasma MDA levels increased five-fold after participants ate a high fat meal and drank water, while plasma MDA levels had only a minimal increases when participants ate the same high fat meal served up with red wine. Similar results were obtained for MDA accumulation in urine. The conclusions is that RWP exerts a benefit effect related to the absorption of the lipotoxin MDA and, consequently, the potentially harmful effect of oxidized fats found in the food and the important benefits of dietary RWP in the meal. As results of the above synthetically described study and other numerous scientific evidences[3-6], red wine, as consequence of its polyphenolic component (RWP), can be considered a functional beverage and/or the raw material for making a number of different functional food and drink products in addition to a variety of RWP based products already on the market to be taken in dietary supplement form. The food and beverage industry is expected to consider using wine and/or concentrated solutions of RWP to

* Corresponding author:

gabriele.digiacomo@univaq.it (Gabriele Di Giacomo)

Published online at http://journal.sapub.org/food

Copyright (C) 2012 Scientific \& Academic Publishing. All Rights Reserved develop new functional beverages other than as a meal additive in unhealthy, fatty food to reduce health risk. This expectation is supported by the huge amount of very good quality red wine which is annually available as surplus in several countries like New Zeeland, Australia, California, Brazil, Chile and all the Mediterranean countries. A well known product already on the market is the so called dealcoholized or non-alcoholic wine (DW) which is actually proposed as succedaneous of wine for people having problems with assumption of alcohol. This work describes a selected reverse osmosis (RO) based process validated at pilot plant scale for making RWP dealcoholized and/or concentrated solutions and pastes to be used as ingredient for developing new antioxidant products for the food and beverage industry other than for the nutraceutical sector.

\section{Raw Materials}

\subsection{Materials}

The wine used was young "Montepulciano d'Abruzzo" (Cantina Citra) from a wine growing area close to Adriatic sea cost (Abruzzo, Italy); with an alcohol content of about $13.5 \%$ b.v., and a total polyphenols content of about $2.3 \mathrm{~g} / \mathrm{l}$. This last concentration was determined by the Folin-Ciocalteau method[4], The Folin-Ciocalteau reagent was from Merck KgaA Darmstadt, Germany, and concentrations were expressed as gallic acid equivalent in milligrams per liter. Absorbance at $765 \mathrm{~nm}$ (spectrophotometer PerkinElmer's Lambda 25 UV/Vis) of wine samples (diluted 1:10) were measured in duplicate, and polyphenol concentrations of samples were derived from a standard curve of gallic acid. 


\subsection{Criteria for Raw Materials Choice}

It is well known that the most active compounds of RWP are quercetin, a natural occurring flavonol, catechin, a natural occurring flavan, and the trans-form of resveratrol, a non-flavonoid also called phitoalexin. This compounds are produced naturally by several plants and may be found abundantly in many fruits and vegetables like capers, lovage, tea, onions, red grapes, citrus fruits, broccoli and other leafy green vegetables, cherries, a number of different berries, organically tomatoes, other than in the roots of white hellebore and Japanese knotweed[5]. In grapes, polyphenols are concentrated primarily in the skin and in the seeds in a quantity related to the grape cultivar, its geographic origin, and exposure to fungal infection[7]. The amount of fermentation time a wine spends in contact with grape skins, along with the maceration mode (carbonic or traditional) and the aging process, are important determinants of its polyphenols content both as quantity and as quality. By considering the results of an experimental work which compares the total antioxidant activity (TA) of red aged wines and vini novelli [8], it may be interesting to point out that aging (and not the wine-making technique) is the main factor influencing the antioxidant activity of the red wines obtained by the same cultivars. Concerning the choice of using red grape juice or red wine as raw material it is interesting to note that the osmotic pressure of the red wine is much lower than that of red grape juice, while the polyphenolic fraction is higher in red wine than in the red grape juice. The big advantage of using red wine as raw material instead of red grape juice will be quite clear in the next section devoted to the description of the polyphenolic recovering process. Here it will be sufficient to underline that using red wine allows one to avoid any kind of up-stream operation, while the same is not true if one uses red grape juice or any other material cited above. The only problems in using red wine for recovering active polyphenols at high concentration, is the requirement of the almost complete removal of ethanol, in particular when the process includes a freezing drying section.

\section{Process and Product}

Dealcoholized and non-alcoholic red wine is the most popular RWP based dietary supplement, already produced and diffused all around the world. It is also considered a succedaneous of wine for people having problems in assuming ethanol. These products are obtained by properly processing red wine in order to selectively remove its ethanol content to less than 0.5 and $0.2 \%$ by volume, respectively. Then, some ingredients like grape vegetation water and/or grape juice along with small quantities of natural concentrated flavors and/or soluble fibers, are added to the RWP liquid solution in order to try to rebuilt the main characteristics of the original wine with particular care for the body, significantly damaged by the removal of the ethanol.

There are a number of technologies which allow one to remove, almost quantitatively, the alcoholic fraction of a liquid solution and, in particular, of the red wine. Among these, distillation is, by the far, the most well known and it is extensively applied when values of temperatures higher than $25-30^{\circ} \mathrm{C}$ are not a problem for the quality and/or the functionality of the product. Low pressure distillation may be a solution to overcome these problems; however it is not practical (from both costs and energy consumption points of view) to remove ethanol at so low temperature and selectivity is also low since all the flavoring compounds of the wine lighter than ethanol are lost with the distillate stream. Dialysis of red wine by using reverse osmosis modules and desalted water is also a quite diffused technology in this field. However, in this case the addition of an extraneous component, can appears as a kind of contamination and, the permeate (a quite dilute aqueous solution of ethanol), is of little value if it is not an environmental problem since, due to its high COD value, it cannot be directly discharged as waste water. In a previous work[9], one of the author of this paper, reported and described a supercritical carbon dioxide continuous extraction process validated at pilot plant scale by using a $3 \mathrm{~m}$ high packed column having an internal diameter of $80 \mathrm{~mm}$ and filled-up with special raschig rings corrosion resistant. The pilot plant operated with recirculating carbon dioxide just as a real industrial plant, giving a very good product as raffinate and an interesting by-product as extract. Furthermore, the use of carbon dioxide at more than 100 bar, results in a kind of sterilization with an associated significant improvement of the shelf-life of the product. In addition, due to the low critical temperature of carbon dioxide (around $31^{\circ} \mathrm{C}$ ), the operation can be performed at less than $40^{\circ} \mathrm{C}$ and, consequently, any temperature damage of active compounds is avoided. However, both investment and running costs are very high compared to competiting technologies like the above mentioned low pressure distillation, the dialysis with reverse osmosis modules and the spinning cone column[10,11].

When looking for the best technology, it is necessary to account for a number of constrains like: a) selectivity; b) investment and running costs; c) value of operating pressure and temperature to minimize any kind of damage to the active compounds and to contribute to a better shelf-life of the products; d) valorization of the removed alcoholic fraction; e) avoiding any kind of contamination of the product.

An interesting new process which can meet all the above mentioned requirements, developed and validated at pilot plant scale during this study, is schematically shown in Figure 1.

As can be seen, it was obtained by properly coupling the dialysis made by a reverse osmosis pilot plant described in a previous paper[12] equipped with modules GEA TFC 3838 spiral wound, with a continuous atmospheric distillation pilot plant, thus taking both the advantages of a simple reverse osmosis based dialyzing (DRO) process with the advantages of a simple atmospheric distillation (AD) process. Red wine is initially charged into one of at least two W/DLS tank and from here it is fed, with the help of an high pressure pump, to the dialysis made by the reverse osmosis (DRO) section where it is concentrate from 10 to 
15 time. The permeate stream is mainly done by an aqueous solution of ethanol with small amount of low molecular weight organic components having a rejection factor comparable to that of water and ethanol. It can be assumed that both RWP, salts and most of higher molecular weight organic molecules of the red wine have a rejection factor quite close to one as a result of the chemical analysis in addition to the sensorial evidence that this stream, up to the above indicated concentration factors, is perfectly uncolored and just a little fragrant as a consequence of its ethanol concentration and of the grape variety used for making the raw material. The second stream coming out from the DRO section is the so called retentate which is made by all the compounds characterized by a rejection factor close to one like salts, RWP, and other high molecular weight organic compounds, in addition to a residual amount of water and ethanol. The permeate stream is fed to an atmospheric distillation column $(\mathrm{AD})$ in order to separate water from ethanol and other volatile compounds. The vegetable water obtained at the bottom is recirculated back to the W/DLS tank along with the retentate stream in order to continue the dialyzing process up to the ethanol concentration into the W/DLS tank is lower than 0.5 or alternatively $0.2 \%$ by volume. The volume of the liquid solution in this vessel is always lower than that of the red wine initially charged since practically all the ethanol is missed; in addition a quantity of vegetation water is also missed depending on the performance of the enriching section of the distillation column during all the time required by the above described process. Actually, the difference between the initial and the final volume of the liquid solution into the W/DLS tank is in the range between 18 and 20\%. As shown in Figure 1, this product can be further processed and used for making a variety of RWP based products. If one has to produce DW and/or non-alcoholic wine, a portion of this solution can be further concentrated to produce the required vegetation water to reproduce the same concentration that RWP and salts have in the red wine. As a consequence, a concentrated (2-3\%) liquid solution of RWP is obtained; it can be used directly in this form or, alternatively, can be further processed in a freezing drying section to produce a much more concentrated paste useful to make capsules and other similar commercial products characterized by an high concentration (more than $40 \%$ ) of RWP [13]. The most interesting by product is the spirit obtained as distillate from the atmospheric distillation column; it is characterized by an high quality level since it was obtained by an high quality raw material and, for this reason, it can be addressed to the industry of spirits for making a variety of both traditional and new products. A second by product could be represented by the vegetation water when DW and/or non-alcoholic wine are not the main product of the described process; it may be useful to point out that this water is particularly pure from microbiological point of view since it was obtained as permeate in the DRO section. For this reason it could be used for making special mineral water and/or used by the soft drinks industry. As final remark it may be useful to underline that both the DRO and the $\mathrm{AD}$ sections can be operated in perfectly continuous mode, provided that at least two W/DLS tanks are used, thus achieving an high productivity.

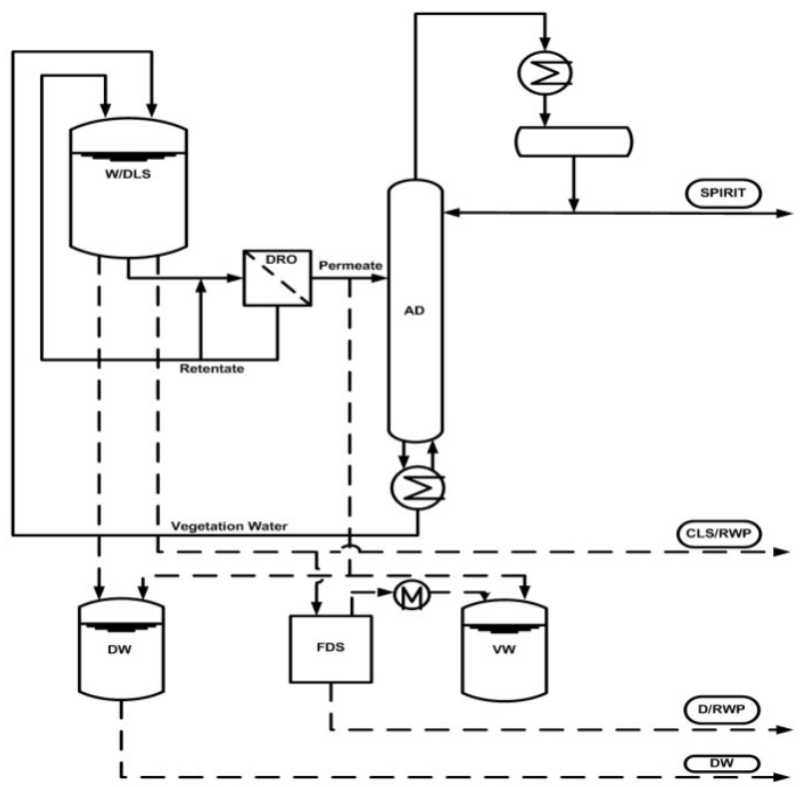

Figure 1. Schematic flow diagram of the RO based process for the production of a functional, uncontaminated and dealcoholized liquid solution of RWP. Dashed lines indicate the streams that can be activated at the end of the primary process (W/DLS: Wine/Dealcoholized Liquid Solution; DRO: Dialysis Reverse Osmosis; AD: Atmospheric Distillation; DW: Dealcoholized Wine; VW: Vegetation Water; FDS: Freez-Drying Section; CLS/ RWP: Concentrated Liquid Solution of RWP; D/RWP: Dehydrated RWP)

\section{Conclusions}

The new integrated process for recovering polyphenols from red wine developed and described in this study is characterized by a number of interesting advantages in comparison to competitive technologies. In particular the use of a traditional DRO section in combination with a traditional $\mathrm{AD}$ section allow one to take the best from both of these consolidated technologies in terms of:

a) production of a dealcoholized liquid solution characterized by a significant shelf-life as a consequence of the intrinsic bactericidal properties of RWP;

b) reasonable low investment and running costs as a consequence of using consolidated and widely diffused technologies;

c) elimination of any kind of contamination as a consequence of using the vegetation water in the DRO section;

d) possibility of operating the DRO section with a very high concentration factor as a consequence of the low solid solute concentration in the wine in comparison with that of the grape juice;

e) production of two interesting by-products which can be easily and profitably valorized by the beverage and spirits industry, thus contributing positively to the economic balance of the whole operation;

f) elimination of any kind of thermal damage of the recovered RWP as consequence of the possibility of process- 
ing RWP rich liquid solutions at ambient temperature and of distilling only liquid solutions free of thermal sensitive compounds.

\section{REFERENCES}

[1] GORELIK, S.; LIGUMSKY, M.; KOHEN, R.; KANNER, J. A novel function of red wine polyphenols in humans: prevention of absorption of cytotoxic lipid peroxidation products. The FASEB J., vol. 22, p. 41-46, 2008.

[2] RENAUD, S.; DE LORGERIL, M. Wine alcohol, platalets and the French paradox for coronary heart disease. Lancet, vol. 339, p. 1523-1526, 1992.

[3] BAUR, J.A.; PEARSON, K.J. Resveratrol improves Health and survival of mice on a high-calorie diet. Nature, vol. 444, p. 337-342, 2006.

[4] CAMUSSONI, G.; CARNEVALI, E. Determinacióncompar ativa del contenido de polifenoles en vinos tintos de origen argentino. Invenio, 7, 151-159; 2004.

[5] VAN GOLDE, P.H.; VAN DER WESTELAKEN, M.; BOUMA, B.N.; VAN DER WIEL, A. Characteristics of piraltin, a polyphenols concentrate, produced by freez-drying of red wine. Life Sciences, vol. 74, n. 9, p. 1159-1166, 2004.

[6] PAIXÃO, N.; PERESTRELO, R.; MARQUES, J.C.; CÂMARA, J.S. Relationship between antioxidant capacity and total phenolic content of red, rosé and white wines. Food Chemistry, vol. 105, n. 1, p. 204-214, 2007.

[7] ROY, H.; LUNDY, S. Resveratrol. Pennington Nutrition Series, n. 7, 2005.

[8] PELlEGRINI, N.; SIMONETTI, P.; GARDANA, C.; BRENNA, O.; BRIGHENTI, F.; PIETTA, P. Polyphenol content and total antioxidant activity of vini novelli (young red wines). J. Agric. Food Chem., vol. 48, p. 732-735, 2000.

[9] DI GIACOMO, G.; DEL RE, G. Continuous fractionation of wine with dense carbon dioxide. In: SUPERCRITICAL FLUIDS MATERIALS AND NATURAL PRODUCTS PROCESSING, 1998, Nice. Proceedings of the 5th Meeting, tome 2, p. 425-430, 1998, ISBN 2-905-267-28-3, 1998.

[10] CASIMIR, D.J.; KRAIG, A.J. Flavour recovery using the Australian spinning cone column. Engineering and Food, vol.3, p. 106-117, 1990.

[11] SYKES, S.J.; PRINCE, R.G.H. Design of spinning cone distillation columns. Inst. Chem. Eng. Symp. Ser. 128 (Distillation and Absorption '92, Vol. 1) p. 167-179, 1992.

[12] DI GIACOMO, G.; TAGLIERI, L. A new high-yield process for the industrial production of carrot juice. Food and Bioprocess Technology, vol. 2, p. 441-446, 2009.

[13] SANCHEZ, V.; BAEZA, R.; GALMARINI, V.M.; ZAMORA, M.C.; CHIRIFE, J. Freeze-Drying Encapsulation of Red Wine Polyphenols in an Amorphous Matrix of Maltodextrin. Food and Bioprocess Technology. DOI 10.1007/ s11947-011-0654-z, 2011. 